\title{
A new diagnostic for tropospheric ozone production
}

\author{
Peter M. Edwards ${ }^{1}$ and Mathew J. Evans ${ }^{1,2}$ \\ ${ }^{1}$ Wolfson Atmospheric Chemistry Laboratories, Department of Chemistry, University of York, \\ Heslington, York, YO10 5DD, UK \\ ${ }^{2}$ National Centre for Atmospheric Science, Department of Chemistry, University of York, \\ Heslington, York, YO10 5DD, UK
}

Correspondence to: Peter M. Edwards (pete.edwards@york.ac.uk)

Received: 25 April 2017 - Discussion started: 1 June 2017

Revised: 18 September 2017 - Accepted: 13 October 2017 - Published: 17 November 2017

\begin{abstract}
Tropospheric ozone is important for the Earth's climate and air quality. It is produced during the oxidation of organics in the presence of nitrogen oxides. Due to the range of organic species emitted and the chain-like nature of their oxidation, this chemistry is complex and understanding the role of different processes (emission, deposition, chemistry) is difficult. We demonstrate a new methodology for diagnosing ozone production based on the processing of bonds contained within emitted molecules, the fate of which is determined by the conservation of spin of the bonding electrons. Using this methodology to diagnose ozone production in the GEOS-Chem chemical transport model, we demonstrate its advantages over the standard diagnostic. We show that the number of bonds emitted, their chemistry and lifetime, and feedbacks on $\mathrm{OH}$ are all important in determining the ozone production within the model and its sensitivity to changes. This insight may allow future model-model comparisons to better identify the root causes of model differences.
\end{abstract}

\section{Introduction}

The chemistry of the troposphere is one of oxidation (Levy, 1973; Kroll et al., 2011). Organic compounds together with nitrogen- and sulfur-containing molecules are emitted into the troposphere where they are oxidised into compounds which can either be absorbed by the biosphere, be involatile enough to form aerosols, deposit to the surface, or be taken up by clouds and rained out. The oxidation of these compounds is significantly slower than might be expected based on the atmospheric composition of $20 \%$ molecular oxygen $\left(\mathrm{O}_{2}\right)$.
The inefficiency of ground-state $\mathrm{O}_{2}$ as an atmospheric oxidant are due to its electronic structure. In quantum mechanics, all atomic particles have an intrinsic angular momentum known as spin (Atkins and De Paula, 2014). The spin of an electron is described by the spin quantum number, $s$, and can have values of either $+1 / 2$ or $-1 / 2$ for a single electron. The Pauli exclusion principle states that if two electrons occupy the same orbital, then their spins must be paired and thus cancel. With two unpaired electrons, ground-state $\mathrm{O}_{2}$ is a spin triplet with a total spin quantum number $S=1 / 2+1 / 2=1$ (giving a term symbol of ${ }^{3} \Sigma_{g}^{-}$). In contrast, virtually all trace chemicals emitted into the atmosphere contain only paired electrons and are thus spin singlets $(S=0)$. The quantum mechanical spin selection rule $\Delta S=0$ means that allowed electronic transitions must not result in a change in electron spin. From a simplistic perspective (i.e. ignoring nuclear spin interactions, inter-system crossings, nuclear dipole effects, etc.) this spin selection rule means that the reaction of ground-state $\mathrm{O}_{2}$ with most emitted compounds is effectively spin forbidden. Electronically excited $\mathrm{O}_{2}\left({ }^{1} \Delta_{g}\right.$ or $\left.{ }^{1} \Sigma_{g}^{+}\right)$is a spin singlet and is more reactive in the atmosphere, but low concentrations limit its role (Larson and Marley, 1999). Instead, atmospheric oxidation proceeds predominantly via reactions with spin-doublet oxygen-derived species $(S=1 / 2)$, notably the hydroxyl $(\mathrm{OH})$ and peroxy radicals $\left(\mathrm{RO}_{2}=\mathrm{HO}_{2}\right.$, $\mathrm{CH}_{3} \mathrm{O}_{2}, \mathrm{C}_{2} \mathrm{H}_{5} \mathrm{O}_{2}$, etc.) or spin-singlet species (e.g. ozone $\left(\mathrm{O}_{3}\right)$ ).

One of the few spin-triplet species in the atmosphere other than $\mathrm{O}_{2}$ is the ground state of atomic oxygen $\left(\mathrm{O}\left({ }^{3} \mathrm{P}\right)\right)$, which readily undergoes a spin-allowed reaction with $\mathrm{O}_{2}$ to produce the spin-singlet $\mathrm{O}_{3}$ molecule. This spin-allowed reaction is responsible for the creation of $\mathrm{O}_{3}$ in both the strato- 
sphere, where it forms the protective $\mathrm{O}_{3}$ layer, and the troposphere. The ability of $\mathrm{O}_{3}$ to oxidise other spin-singlet species makes it a powerful oxidant, and it is thus considered a pollutant with negative health effects. Sources of $\mathrm{O}\left({ }^{3} \mathrm{P}\right)$ within the troposphere are limited because solar photons at sufficiently short wavelengths to directly photolyse $\mathrm{O}_{2}$ to $\mathrm{O}\left({ }^{3} \mathrm{P}\right)$ are essentially unavailable.

Aside from the photolysis of $\mathrm{O}_{3}$ itself, the only other significant source of tropospheric $\mathrm{O}\left({ }^{3} \mathrm{P}\right)$ is the photolysis of nitrogen dioxide $\left(\mathrm{NO}_{2}\right)$ (Crutzen, 1971). Nitrogen oxides are emitted into the troposphere as nitrogen oxide (NO), which can be oxidised to $\mathrm{NO}_{2}$ by $\mathrm{O}_{3}$ and other oxidants. A large thermodynamic energy barrier prevents the oxidation of $\mathrm{NO}$ to $\mathrm{NO}_{2}$ by the $\mathrm{OH}$ radical (Nguyen et al., 1998), and therefore $\mathrm{NO}$ oxidation occurs through reaction with either $\mathrm{O}_{3}$ or $\mathrm{RO}_{2}$. In terms of $\mathrm{O}_{3}$ production, the oxidation of $\mathrm{NO}$ by $\mathrm{O}_{3}$ forms a null cycle. Thus, only the reaction of $\mathrm{NO}$ with $\mathrm{RO}_{2}$ leads to a net production of $\mathrm{O}_{3}$.

Exploring the distribution, source and sinks of tropospheric $\mathrm{O}_{3}$ is a central theme of atmospheric science. Chemical transport models (online and offline) are essential tools enabling this understanding, but their validity needs to be continually assessed. Model-model comparison exercises are commonly performed to assess performance, and comparisons of modelled $\mathrm{O}_{3}$ budgets traditionally form part of this assessment (Stevenson et al., 2006; Wu et al., 2007; Wild, 2007; Young et al., 2013). Ozone production is diagnosed from the flux of $\mathrm{NO}$ to $\mathrm{NO}_{2}$ via reaction with each of the speciated $\mathrm{RO}_{2}$ in the model's chemical schemes. This approach provides information on the relative importance of the different $\mathrm{RO}_{2}$ in the fast $\mathrm{NO}+\mathrm{RO}_{2}$ reactions within the model but gives very little detail on how the longer-timescale model processes (emissions, chemistry, deposition) influence $\mathrm{O}_{3}$ production. Thus, exploring the reasons that models differ in their $\mathrm{O}_{3}$ production is difficult and progress has been slow.

A new diagnostic framework that links large-scale model drivers such as emission, chemistry and deposition to $\mathrm{O}_{3}$ production would allow an improved assessment of why model ozone budgets differ. We attempt to provide such a framework here.

\section{A new diagnostic framework}

The rate of production of tropospheric $\mathrm{O}_{3}$ is limited by the rate of oxidation of $\mathrm{NO}$ to $\mathrm{NO}_{2}$, which is in turn limited by the rate of production of peroxy radicals $\left(\mathrm{RO}_{2}\right)$. Peroxy radicals form through association reactions of hydrogen $(\mathrm{H})$ atoms or alkyl radicals (both spin doublets, $S=1 / 2$ ) with $\mathrm{O}_{2}$, forming a highly reactive spin-doublet radical on an oxygen atom. This spin-allowed reaction converts spin-triplet $\mathrm{O}_{2}$ that cannot react with spin-singlet pollutants into a spindoublet $\mathrm{O}_{2}$-containing species that can. As such the formation of $\mathrm{RO}_{2}$ is central to the atmosphere's oxidation capacity, and its production is limited by the rate of production of $\mathrm{H}$ atoms or alkyl radicals. Thus, the maximum potential rate of tropospheric $\mathrm{O}_{3}$ production is equal to the rate at which $\mathrm{H}$ atoms and alkyl radicals are produced.

Hydrogen atoms and alkyl radicals are predominantly produced via the spin-allowed breaking of the spin pairing between the two electrons in a $\mathrm{C}$ - or $\mathrm{H}$-containing covalent bond $(S=0)$, such as those in hydrocarbons. These spin pairings can be broken in the atmosphere either chemically or photolytically, with the products necessarily conserving spin. The breaking of a covalent bond by a photon $(S=1)$ can result in two products with $S=1 / 2$ or two products with $S=0$. Likewise, oxidation by a radical $(S=1 / 2)$ will result in one product with $S=0$ and one with $S=1 / 2$ because the unpaired electron on the radical reactant pairs with one of the covalent-bond electrons to produce a spin singlet.

Although the majority of $\mathrm{RO}_{2}$ is formed from emitted Cor H-containing covalent bonds, there are a few notable exceptions. Hydrogen atoms can also be produced through the oxidation of $\mathrm{CO}$ to $\mathrm{CO}_{2}$ by $\mathrm{OH}$. During this reaction the coordinate bond between the $\mathrm{C}$ and $\mathrm{O}$ atom is broken and the $\mathrm{H}$ atom is produced via the breaking of the $\mathrm{O}-\mathrm{H}$ bond. The other notable exception is the oxidation of an $\mathrm{SO}_{2}$ lone pair of electrons to $\mathrm{SO}_{3}$ by $\mathrm{OH}$, where again the $\mathrm{H}$ atom produced comes from the $\mathrm{OH}$. In both of these exceptions a spin-singlet electron pairing ( $\mathrm{CO}$ coordinate bond or $\mathrm{SO}_{2}$ lone pair) is broken during the production of the $\mathrm{H}$ atom, and we can therefore consider these reactions similar to the breaking of a $\mathrm{C}$ - or H-containing covalent bond. For simplicity these spin-singlet electron pairings that can be broken in the troposphere to produce either a $\mathrm{H}$ atom or an alkyl radical will be referred to as "oxidisable bonds" $(\mathrm{C}-\mathrm{C}, \mathrm{C}-\mathrm{H}, \mathrm{C}=\mathrm{C}$, CO coordinate bond, $S$ :).

Tropospheric $\mathrm{O}_{3}$ production occurs through the oxidation of $\mathrm{NO}$ by $\mathrm{RO}_{2}$. Following the above rationale, these $\mathrm{RO}_{2}$ are produced during the spin-allowed breaking of oxidisable bonds predominantly contained within emitted volatile organic compounds (VOCs). This perspective allows us to build a new metric for the production of tropospheric $\mathrm{O}_{3}$ based around the spin-conserving properties of oxidisable bond breaking. In the extreme case, all oxidisable bonds are photolysed to produce two spin-doublet $\mathrm{RO}_{2}$ products, which then react exclusively with $\mathrm{NO}$ to generate $\mathrm{O}_{3}$. Thus, at steady state, the maximum rate of $\mathrm{O}_{3}$ production is equal to the rate of production of $\mathrm{RO}_{2}$, which is equal to twice the rate of destruction of the number of oxidisable bonds. This in turn is equal to twice the rate of emission of oxidisable bonds. Deviation from this maximum is determined by

- the relative importance of processes that produce spinsinglet vs. spin-doublet products during oxidisable bond breaking;

- the fraction of spin-doublet products from oxidisable bond breaking which form $\mathrm{RO}_{2}$; 


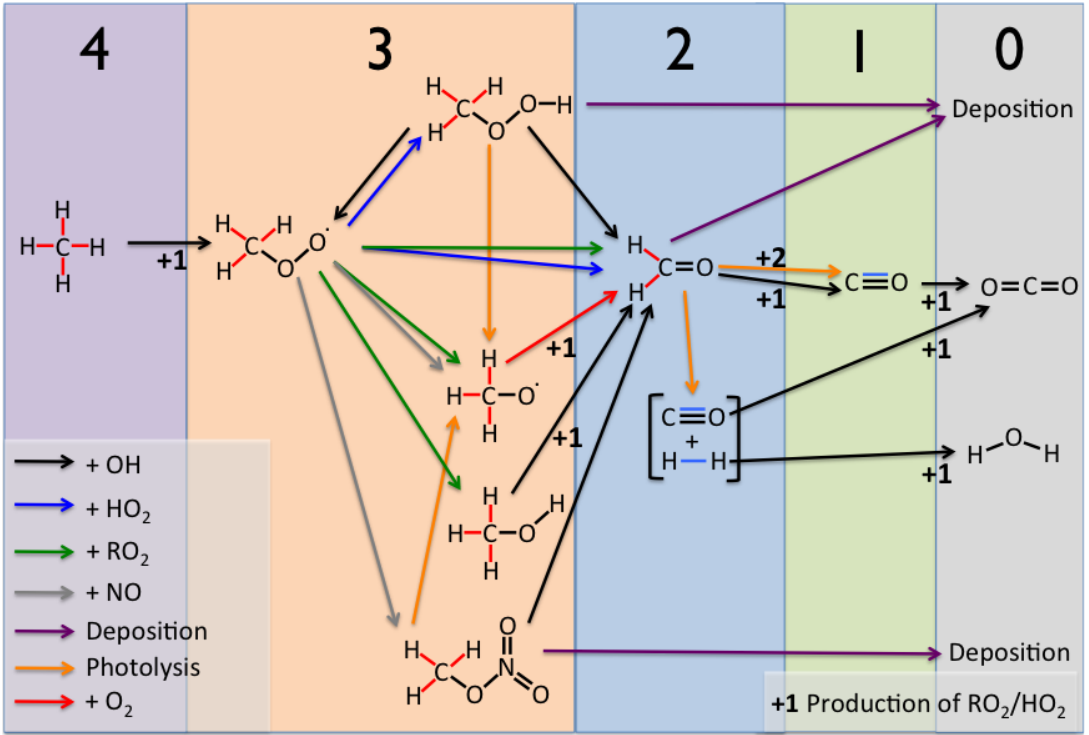

Figure 1. Peroxy radical production during the tropospheric oxidation of $\mathrm{CH}_{4}$. Moving from left to right, the oxidisable bonds (emitted: red; produced: blue) present in $\mathrm{CH}_{4}$ are removed via a range of tropospheric processes, indicated by the coloured arrows. The large numbers across the top of the figure indicate the number of oxidisable bonds at each stage of this oxidation. The production of $\mathrm{RO}_{2}$ is indicated by the $+1 /+2$ numbers with the associated process arrows for producing one or two $\mathrm{RO}_{2}$ respectively.

- the fraction of $\mathrm{RO}_{2}$ that go on to oxidise $\mathrm{NO}$ to $\mathrm{NO}_{2}$.

To illustrate this, Fig. 1 shows the tropospheric oxidation of a methane $\left(\mathrm{CH}_{4}\right)$ molecule through various steps to either a carbon dioxide $\left(\mathrm{CO}_{2}\right)$ molecule or a species that is deposited $\left(\mathrm{CH}_{3} \mathrm{OOH}, \mathrm{CH}_{2} \mathrm{O}, \mathrm{CH}_{3} \mathrm{NO}_{3}\right)$. Methane contains four times $\mathrm{C}-\mathrm{H}$ oxidisable bonds (eight paired bonding electrons) and as the oxidation proceeds, the number of oxidisable bonds decays to 0. Figure 1 highlights the steps in the tropospheric $\mathrm{CH}_{4}$ oxidation mechanism that form spindoublet products, with between one and $5 \mathrm{RO}_{2}$ produced depending on the oxidation pathway. This compares with the theoretical maximum of eight if all the original $\mathrm{C}-\mathrm{H}$ bonds were photolysed to yield two spin-doublet products.

The principal atmospheric source of oxidisable bonds is the emission of $\mathrm{C}-\mathrm{H}, \mathrm{C}-\mathrm{C}$ and $\mathrm{C}=\mathrm{C}$ bonds in hydrocarbons, with the only other significant sources being the emission of $\mathrm{CO}$ and the chemical production of $\mathrm{CO}$ and $\mathrm{H}_{2}$ during hydrocarbon oxidation. Over a long enough timescale, the global atmosphere can be considered to be in a chemical steady state, where the rate of loss of oxidisable bonds is balanced by the rate of production or emission. Thus, the $\mathrm{O}_{3}$ production rate can be described by Eq. (1), where the $\mathrm{O}_{3}$ production metric $P_{\mathrm{s}} \mathrm{O}_{3}$ is equal to the number of spinpaired electrons in oxidisable bonds (i.e. twice the sum of the number of oxidisable bonds emitted, $E_{\text {bonds }}$, and chemically produced, $\left.P_{\text {bonds }}\right)$, multiplied by the number of spin-doublet radicals produced per oxidisable bond break divided by the maximum of 2 ( $F_{\text {Radicals }}$ ), in turn multiplied by the fraction of the radicals produced which are $\mathrm{RO}_{2}\left(F_{\mathrm{RO}_{2}}\right)$, multiplied by the fraction of $\mathrm{RO}_{2}$ that goes on to react with an $\mathrm{NO}$ to produce an $\mathrm{O}_{3}$ molecule $\left(F_{\mathrm{NO}}\right)$. A small correction $(I)$ for the production of $\mathrm{RO}_{2}$ via reactions of spin-doublet radicals other than those that result in the breaking of oxidisable spin pairings (e.g. $\mathrm{O}_{3}+\mathrm{OH} \rightarrow \mathrm{HO}_{2}+\mathrm{O}_{2}$ ) is included.

$$
\begin{aligned}
P_{\mathrm{s}} \mathrm{O}_{3}= & \left(\left(2 \times\left(E_{\text {bonds }}+P_{\text {bonds }}\right) \times F_{\text {radicals }} \times F_{\mathrm{RO}_{2}}\right)+I\right) \\
& \times F_{\mathrm{NO}}
\end{aligned}
$$

\section{Implementation}

We use the GEOS-Chem model to evaluate this new $\mathrm{O}_{3}$ production diagnostic. GEOS-Chem is a global chemical transport model of tropospheric chemistry, aerosol and transport (http://www.geos-chem.org version 9-02). The model is forced by assimilated meteorological and surface fields (GEOS-5) from NASA's Global Modelling and Assimilation Office and was run at $4^{\circ} \times 5^{\circ}$ spatial resolution. The model chemistry scheme includes $\mathrm{O}_{x}, \mathrm{HO}_{x}, \mathrm{NO}_{x}, \mathrm{BrO}_{x}$ and VOC chemistry as described in Mao et al. (2013) as are the emissions. The new $P_{\mathrm{s}} \mathrm{O}_{3}$ diagnostic has been implemented via the tracking of reactions by type in the GEOS-Chem chemical mechanism file (further details given in the Supplement). This tracking of reactions enables the fate of all oxidisable bonds as well as the production and loss of all $\mathrm{RO}_{2}$ within the model to be determined using the standard GEOS-Chem production and loss diagnostic tools. Model simulations were run for 2 years (1 July 2005-1 July 2007) with the first year used as a spin-up and the diagnostics performed on the second year. 


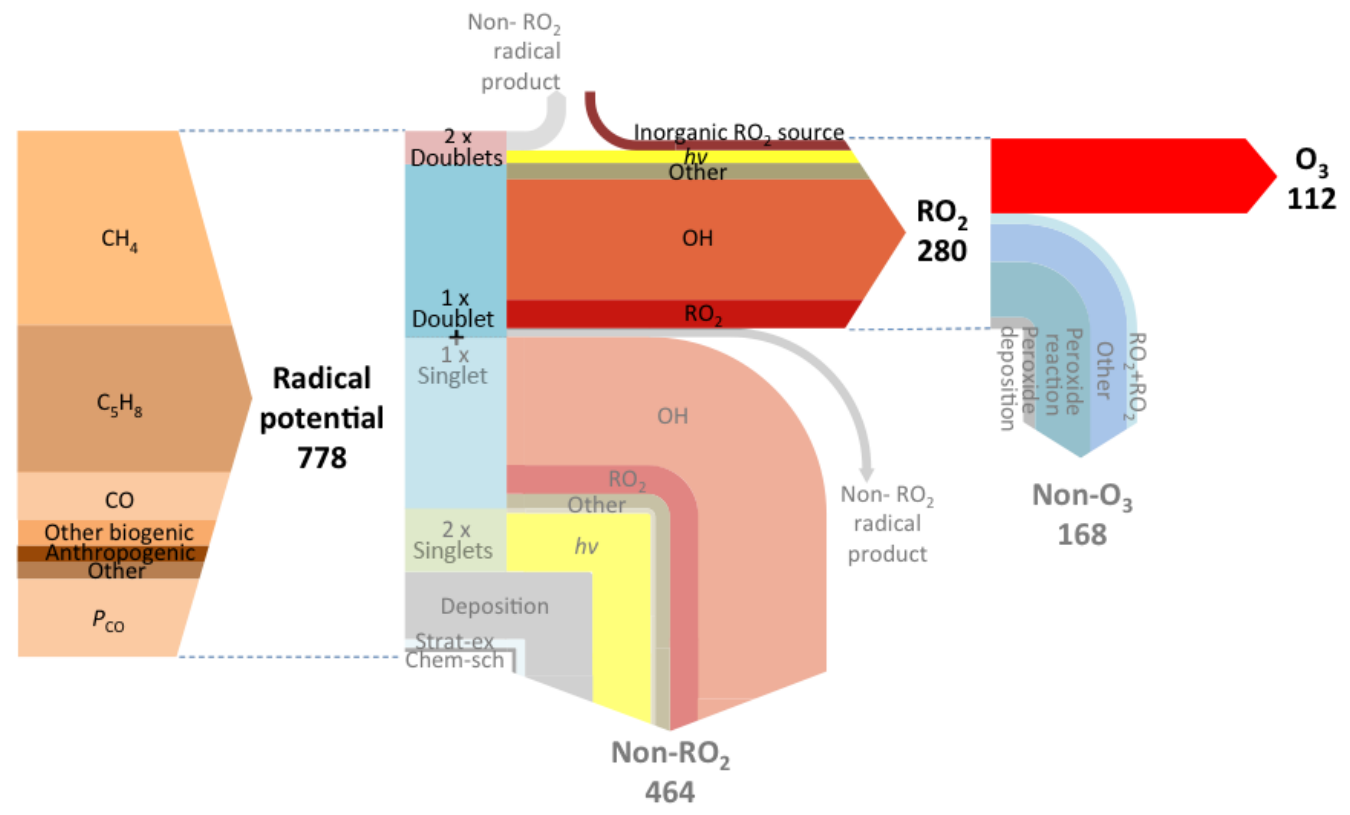

Figure 2. Flow of oxidisable bonds to $\mathrm{O}_{3}$ production in the GEOS-Chem base simulation. Arrows are coloured according to process, and the arrow thickness is proportional to the flux through that channel. Spin-paired electrons are input as oxidisable bonds into the model (left arrow), with the potential to create $778 \mathrm{~T} \mathrm{~mol} \mathrm{yr}^{-1}$ of radicals. The actual fate of these bonds is shown in the central arrow, producing $280 \mathrm{~T} \mathrm{~mol} \mathrm{yr}^{-1}$ of $\mathrm{RO}_{2}$, of which $112 \mathrm{~T} \mathrm{~mol} \mathrm{yr}^{-1}$ reacts with $\mathrm{NO}$ to produce $\mathrm{O}_{3}$ (right arrow).

The standard GEOS-Chem diagnostic for $\mathrm{O}_{3}$ production $\left(P_{3}\right)$ is shown on the left side of Table 1. This emphasises the very fast cycling between $\mathrm{NO}$ and $\mathrm{NO}_{2}$, but provides little in terms of higher process-level information. The right side of Table 1 shows the new budget for $P_{\mathrm{s}} \mathrm{O}_{3}$, which tracks the processing of oxidisable bonds within the model. Both diagnostic methods give the same final answer, but our new methodology provides more process-level detail. Figure 2 illustrates this new process-based approach, showing the flow of emitted oxidisable spin-paired electrons (bonds) to $\mathrm{O}_{3}$ and the magnitude of the various mechanisms that contribute to and compete with $\mathrm{O}_{3}$ production. The annual oxidisable bond emission of $389 \mathrm{~T} \mathrm{~mol} \mathrm{yr}^{-1}$ has the potential to create $778 \mathrm{~T} \mathrm{~mol} \mathrm{yr}^{-1}$ of radicals. If all oxidisable bonds were broken by photons to produce two radical products, the $\mathrm{RO}_{2}$ production would be $778 \mathrm{~T} \mathrm{~mol} \mathrm{yr}^{-1}$. If the oxidisable bonds were instead broken via radical reaction (e.g. OH), then $\mathrm{RO}_{2}$ production would be $389 \mathrm{~T} \mathrm{~mol} \mathrm{yr}^{-1}$. The various oxidisable bond-breaking/removal pathways within the model result in the production of $280 \mathrm{~T} \mathrm{~mol} \mathrm{yr}^{-1}$ of $\mathrm{RO}_{2}$, with the remainder largely producing stable spin-singlet products.

Of the $280 \mathrm{~T} \mathrm{~mol} \mathrm{yr}^{-1} \mathrm{RO}_{2}$ produced, $112 \mathrm{~T} \mathrm{~mol} \mathrm{yr}^{-1}$ reacts with $\mathrm{NO}$ to produce $\mathrm{O}_{3}$. The remainder is lost through the reaction or deposition of $\mathrm{RO}_{2}$ reservoir species $\left(\mathrm{RO}_{2 y}=\mathrm{RO}_{2}+\right.$ peroxides + peroxy-acetyl nitrates). For example the production of methylperoxide $\left(\mathrm{CH}_{3} \mathrm{O}_{2}+\mathrm{HO}_{2}=\mathrm{CH}_{3} \mathrm{OOH}\right)$ results in the loss of two $\mathrm{RO}_{2} \mathrm{~s}$. However, the reaction of methylperoxide with $\mathrm{OH}$ can rerelease $\mathrm{CH}_{3} \mathrm{O}_{2}\left(\mathrm{CH}_{3} \mathrm{OOH}+\mathrm{OH}=\mathrm{CH}_{3} \mathrm{O}_{2}+\mathrm{H}_{2} \mathrm{O}\right)$. Thus,
Table 1. Comparison of ozone production diagnostics for GEOSChem base simulation. Standard model $\mathrm{PO}_{3}$ diagnostics (left column) show reactions responsible for $\mathrm{NO}$ to $\mathrm{NO}_{2}$ conversions but provide little process-level information. The new $P_{\mathrm{S}} \mathrm{O}_{3}$ (right) provides increased information on the processes controlling $\mathrm{O}_{3}$ production within the model.

\begin{tabular}{lr|lr}
\hline \multicolumn{1}{c|}{$\mathrm{PO}_{3} / \mathrm{T} \mathrm{mol} \mathrm{yr}^{-1}$} & & \multicolumn{2}{c}{$\mathrm{PO}_{3} / \mathrm{T} \mathrm{mol} \mathrm{yr}^{-1}$} \\
& & $F_{\mathrm{NO}}$, which are all unitless $)$ \\
\hline $\mathrm{NO}+\mathrm{HO}_{2} \rightarrow \mathrm{NO}_{2}$ & 74 & $E_{\text {bonds }}$ & 330 \\
$\mathrm{NO}+\mathrm{CH}_{3} \mathrm{O}_{2} \rightarrow \mathrm{NO}_{2}$ & 27 & $P_{\text {bonds }}$ & 58 \\
Other $\mathrm{RO}_{2}+\mathrm{NO} \rightarrow \mathrm{NO}_{2}$ & 10 & $F_{\text {radicals }}$ & 0.40 \\
Other & 1 & $F_{\mathrm{RO}_{2}}$ & 0.86 \\
& & Inorganic $\mathrm{RO}_{2}$ source & 15 \\
& & $F_{\mathrm{NO}}$ & 0.40 \\
$\mathrm{PO}_{3}$ & 112 & $P_{\mathrm{S}} \mathrm{O}_{3}$ & 112 \\
\hline
\end{tabular}

the production of methylperoxide represents the loss of a $\mathrm{HO}_{2}$ and the movement of a $\mathrm{CH}_{3} \mathrm{O}_{2}$ into a peroxide $\mathrm{RO}_{2 y}$ reservoir species. The deposition of a peroxide molecule is thus the loss of a $\mathrm{RO}_{2 y}$ reservoir species. Notable in Fig. 2 is that the role of PAN and nitrate removal of global $\mathrm{RO}_{2 y}$ is negligible, instead being dominated by peroxide production and loss and the reaction of $\mathrm{RO}_{2}$ with $\mathrm{O}_{3}$. 

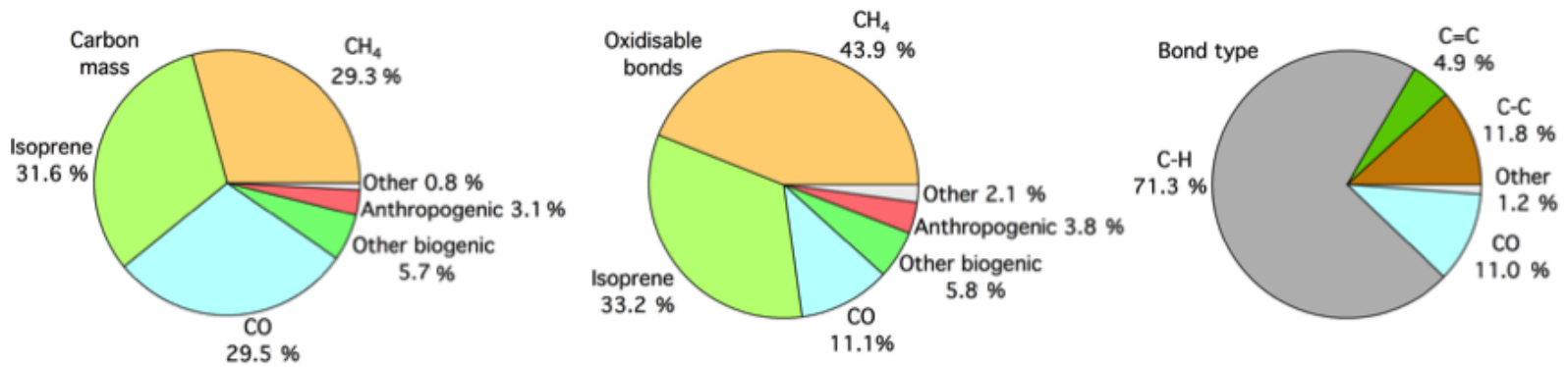

Figure 3. Pie charts showing hydrocarbon emissions in the base GEOS-Chem simulation. Emissions split by carbon mass (left), number of oxidisable bonds (centre), and bond type (right).

\section{Emitted oxidisable bonds}

The fuel for tropospheric oxidation chemistry is the emission of oxidisable bonds, predominantly in the form of hydrocarbons. The production of tropospheric $\mathrm{O}_{3}$ from the spin-paired bonding electrons emitted into the standard GEOS-Chem model occurs with an efficiency of $14 \%$ (112 $\mathrm{T} \mathrm{mol} \mathrm{yr}^{-1}$ molecules of $\mathrm{O}_{3}$ produced/778 $\mathrm{T} \mathrm{mol} \mathrm{yr}^{-1}$ spin-paired electrons emitted as oxidisable bonds; Fig. 2). These spin-paired bonding electrons are predominantly emitted in the form of $\mathrm{CH}_{4}$, isoprene $\left(\mathrm{C}_{5} \mathrm{H}_{8}\right)$ and $\mathrm{CO}(37,28$ and $9 \%$ respectively). Oxidisable bonds produced during chemical reactions $\left(P_{\text {bonds }}\right)$ account for $15 \%$ of the net source. Figure 3 shows emissions of $\mathrm{CO}$ and hydrocarbons in the standard GEOS-Chem simulation in terms of mass of carbon per compound, as the number of oxidisable bonds per compound and as the number of bonds in different oxidisable bond types. The commonly used carbon mass approach splits emissions approximately equally between each of the major sources $\left(\mathrm{CH}_{4}, 29 \%\right.$; isoprene, $32 \%$; and $\left.\mathrm{CO}, 30 \%\right)$. In contrast, the oxidisable bonds accounting approach apportions hydrocarbon emissions of 44,33 and $11 \%$ for $\mathrm{CH}_{4}$, isoprene and $\mathrm{CO}$ respectively. This highlights the high number of oxidisable bonds per carbon atom in $\mathrm{CH}_{4}$ (4) compared to isoprene (2.8) and CO (1). Thus, efforts to consider emissions on a per-bond basis may provide more insight into chemical processes, as it is these bonds that ultimately determine the chain-like chemistry rather than the mass of carbon atoms. This helps to emphasise the relative importance of $\mathrm{CH}_{4}$ emissions in global tropospheric chemistry compared with other emissions such as isoprene or CO. The type of oxidisable bond emitted is overwhelmingly $\mathrm{C}-\mathrm{H}(71 \%)$.

The total emission and production of oxidisable bonds has the potential to create $778 \mathrm{~T} \mathrm{~mol} \mathrm{yr}^{-1}$ of radicals. However, only $6 \%$ of the oxidisable spin pairings are broken to give the maximum two spin-doublet products (e.g. radical channel of $\mathrm{CH}_{2} \mathrm{O}$ photolysis). The majority $(68 \%)$ are oxidised via reaction with a spin-doublet species $(\mathrm{OH})$ to produce one spin-singlet and one spin-doublet product (e.g. $\mathrm{OH}+\mathrm{VOC}$ ). The remaining $26 \%$ of spin-paired electrons are removed to form two spin-singlets (e.g. the non-radical channel of
$\mathrm{CH}_{2} \mathrm{O}$ photolysis). Thus, of the $778 \mathrm{~T} \mathrm{~mol} \mathrm{yr}^{-1}$ spin-paired electrons emitted or produced, only $265 \mathrm{~T} \mathrm{~mol} \mathrm{yr}^{-1}(34 \%)$ are converted into $\mathrm{RO}_{2}$, with an additional $15 \mathrm{~T} \mathrm{~mol} \mathrm{yr}^{-1}$ produced from reactions such as $\mathrm{O}_{3}+\mathrm{OH}, \rightarrow \mathrm{HO}_{2}+\mathrm{O}_{2}(I)$. The efficiency of $\mathrm{O}_{3}$ production from the available oxidisable bonds is further reduced as only $40 \%$ of the $280 \mathrm{~T} \mathrm{~mol} \mathrm{yr}^{-1}$ of $\mathrm{RO}_{2}$ produced react with $\mathrm{NO}$ to produce $\mathrm{NO}_{2}$. The remainder is lost either through the self-reaction of $\mathrm{RO}_{2}$ or via loss through deposition or reaction of $\mathrm{RO}_{2 y}$ reservoir species (e.g. peroxides). Thus, overall $14 \%$ of the emitted bonding electrons go on to make $\mathrm{O}_{3}$.

The new $\mathrm{O}_{3}$ production diagnostic presented here $\left(P_{\mathrm{s}} \mathrm{O}_{3}\right)$ shows the impact of processes such as emission, deposition and chemical mechanism and provides significantly more detail than the standard $\mathrm{PO}_{3}$ diagnostic approach (Table 1). We now explore the sensitivity of model $\mathrm{O}_{3}$ production to changing emissions of $\mathrm{NO}_{x}$ and VOC from the perspective of the two diagnostic methods.

\section{Model sensitivities}

Understanding model response to changing emissions is an important tool for considering policy interventions. The major controls on $\mathrm{O}_{3}$ production are emissions of $\mathrm{NO}_{x}$ and VOCs. We show in Fig. 2 that from the perspective of global $\mathrm{O}_{3}$ production, oxidisable bond emissions are dominated by $\mathrm{CH}_{4}$ and isoprene. Figure 4 shows the impact of changing emissions of $\mathrm{NO}_{x}$, isoprene and $\mathrm{CH}_{4}$ on $\mathrm{O}_{3}$ production from both the perspective of this new methodology and the conventional $\mathrm{NO}+\mathrm{RO}_{2}$ diagnostic approach. A set of five simulations was performed for each model sensitivity investigated $\left(\mathrm{NO}_{x}\right.$, isoprene and $\left.\mathrm{CH}_{4}\right)$, with a common base simulation, resulting in 13 simulations in total. The following sections investigate these model responses and use the new diagnostic to provide insight into the processes driving the observed response in $\mathrm{O}_{3}$ production.

\section{1 $\mathrm{NO}_{x}$ emissions}

Figure $4 \mathrm{a}$ diagnoses the relative response of GEOS-Chem $\mathrm{O}_{3}$ production to changing $\mathrm{NO}_{x}$ emissions, using simulations 

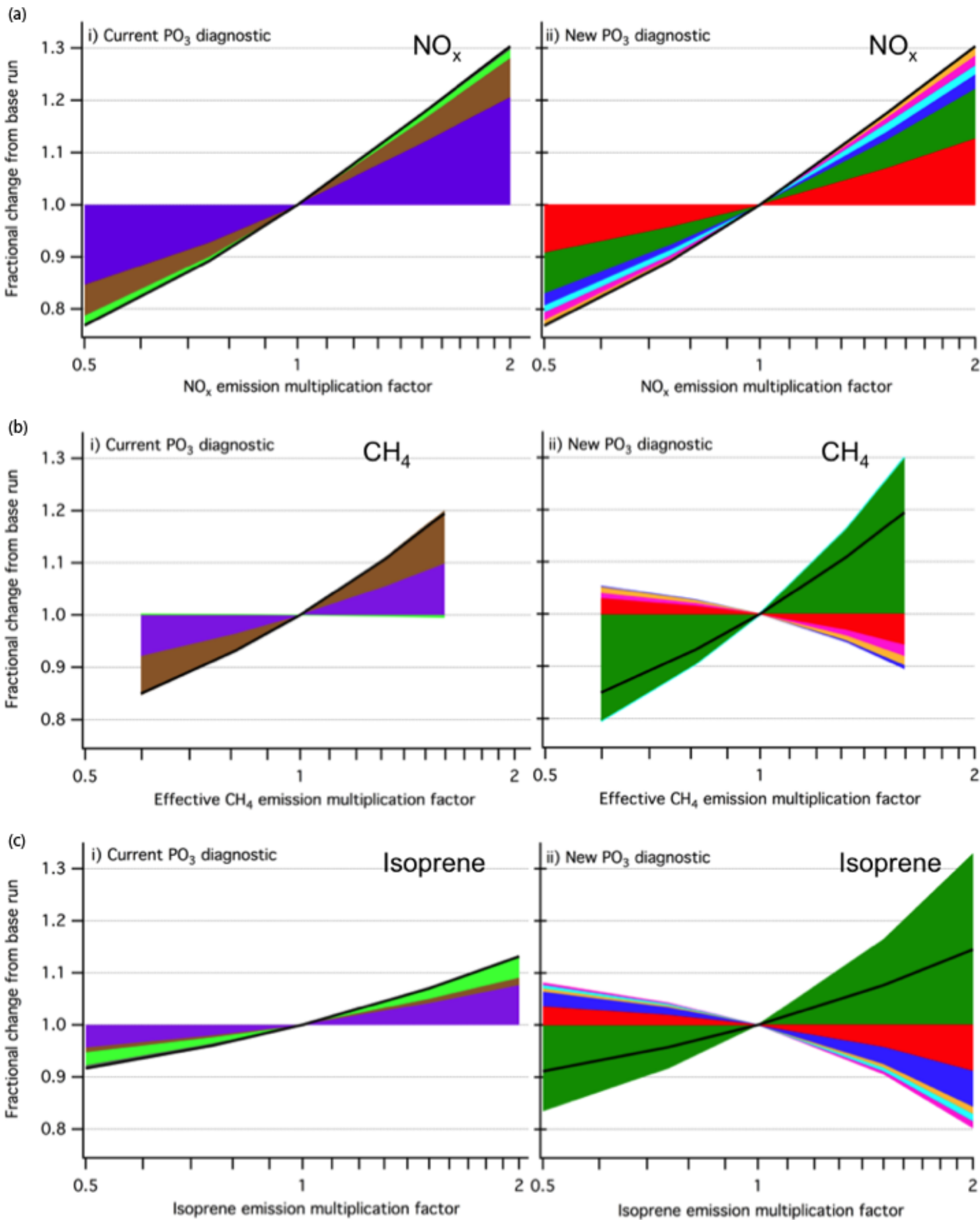

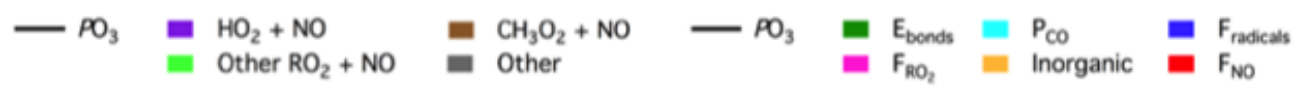

Figure 4. Understanding the effect of $\mathrm{NO}_{x}$ and VOC emissions on ozone production at the process level. Stack plots showing fractional change in model $\mathrm{PO}_{3}$ compared to base simulation and associated contributions from the current $P_{3}$ (i) and new $P_{\mathrm{S}} \mathrm{O}_{3}$ (ii) diagnostic parameters under changing $\mathrm{NO}_{x}$ emissions (a), effective $\mathrm{CH}_{4}$ emission (b) and isoprene emission (c). The $P_{\mathrm{s}} \mathrm{O}_{3}$ diagnostic parameters are derived for each model simulation using the diagnostic implementation described in Sect. 3 and the fractional change in each parameter from the base simulation calculated. 
where $\mathrm{NO}_{x}$ emissions from anthropogenic, biomass burning, biofuels, soil and lighting sources were multiplied by factors of $0.5-2$. Increasing $\mathrm{NO}_{x}$ emissions increases $\mathrm{O}_{3}$ production. The standard $\mathrm{RO}_{2}+\mathrm{NO}$ diagnostic (Fig. 4ai) shows that fractional contributions to the total change in $\mathrm{PO}_{3}$ from $\mathrm{HO}_{2}(67 \%)$, methyl-peroxy $\left(\mathrm{CH}_{3} \mathrm{O}_{2}\right)(25 \%)$ and other $\mathrm{RO}_{2}$ $(8 \%)$ remain approximately constant across the $\mathrm{NO}_{x}$ emission range investigated. This diagnostic provides little detail on the processes driving the change in $\mathrm{O}_{3}$ production under changing $\mathrm{NO}_{x}$ emissions. In contrast, Fig. 4aii is based on the new $P_{\mathrm{S}} \mathrm{O}_{3}$ diagnostic and shows a range of process-level changes occurring as $\mathrm{NO}_{x}$ emissions change.

\subsubsection{Impact of changing $\mathrm{NO}_{x}$ emission on $\boldsymbol{F}_{\mathrm{NO}}$}

Unsurprisingly, as $\mathrm{NO}_{x}$ emissions increase the fraction of $\mathrm{RO}_{2}$ reacting with $\mathrm{NO}$ to produce $\mathrm{NO}_{2}\left(F_{\mathrm{NO}}\right)$ increases (red section in Fig. 4aii). However, this impact only accounts for around $40 \%$ of the increase in $P_{\mathrm{s}} \mathrm{O}_{3}$. Figure 5a shows the fractional change in all the $P_{\mathrm{s}} \mathrm{O}_{3}$ efficiency parameters and the global mean $\mathrm{NO}_{x}$ concentration as a function of the changing $\mathrm{NO}_{x}$ emission. As $\mathrm{NO}_{x}$ emissions increase, the increase in $\mathrm{NO}_{x}$ concentration in the model is somewhat dampened. Halving the $\mathrm{NO}_{x}$ emission leads to $\mathrm{NO}_{x}$ burdens dropping by $\sim 35 \%$, and doubling leads to an increase of $95 \%$. This dampening is due to the impact of $\mathrm{NO}_{x}$ emissions on $\mathrm{OH}$ (see Sect. 4.1.2), which is the dominant sink for $\mathrm{NO}_{x}$. Increasing $\mathrm{NO}_{x}$ increases $\mathrm{OH}$ concentrations, which in turn shortens the $\mathrm{NO}_{x}$ lifetime, thus dampening the response of concentration to emission.

The response of $F_{\mathrm{NO}}$ to changes in $\mathrm{NO}_{x}$ emissions is also dampened relative to the change in $\mathrm{NO}_{x}$ emissions. This is due to spatial variability in $F_{\mathrm{NO}}$, which is not affected uniformly by changing $\mathrm{NO}_{x}$ emissions. Figure 6 shows the probability distribution of $F_{\mathrm{NO}}$ values across all model grid boxes for the base simulation and the half and doubled $\mathrm{NO}_{x}$ emission simulations (black, blue and red lines respectively). For example, in a grid box in the continental boundary layer where $\mathrm{RO}_{2}$ reacts overwhelmingly with $\mathrm{NO}$, doubling the $\mathrm{NO}_{x}$ emission may move $F_{\mathrm{NO}}$ from 0.90 to 0.95 , but it cannot double it. Similarly, in the remote boundary layer where $\mathrm{RO}_{2}$ reacts overwhelmingly with other $\mathrm{RO}_{2}$, doubling $\mathrm{NO}_{x}$ emissions may move $F_{\mathrm{NO}}$ from 0.3 to 0.4 , but again it does not double. Thus, the geographical spread of $\mathrm{NO}_{x}$ chemistry limits the change in $F_{\mathrm{NO}}$ caused by changing $\mathrm{NO}_{x}$ emissions. The spatial variability in the new $P_{\mathrm{s}} \mathrm{O}_{3}$ diagnostic parameters shows that this approach has significant potential in the analysis of regional $\mathrm{O}_{3}$ budgets as well as global.

\subsubsection{Impact of changing $\mathrm{NO}_{x}$ emission on $E_{\mathrm{bonds}}$}

Figure 4aii shows that $60 \%$ of the response in $P_{\mathrm{S}} \mathrm{O}_{3}$ to changing $\mathrm{NO}_{x}$ emission is due to factors other than $F_{\mathrm{NO}}$, with $40 \%$ of the increase due to changes in the emissions ( $E_{\text {bonds }}$ : $32 \%$ ) and chemical production $\left(P_{\text {bonds }}: 8 \%\right.$ ) of oxidisable bonds. This increase in $E_{\text {bonds }}$ is surprising given VOC emissions are unchanged in these simulations. However, increasing $\mathrm{NO}_{x}$ emissions results in an increased $\mathrm{OH}$ concentration in the model, which then leads to an increase in $\mathrm{CH}_{4}$ oxidation. Methane $\left(\mathrm{CH}_{4}\right)$ concentrations are fixed in GEOSChem, resulting in an increase in the effective $\mathrm{CH}_{4}$ emission as $\mathrm{OH}$ concentrations increase, causing an increase in the total bond emission $\left(E_{\text {bonds }}\right)$. Figure 7 shows the response of effective $\mathrm{CH}_{4}$ bond emission to global mean $\mathrm{OH}$ concentration as it changes with global mean $\mathrm{NO}_{x}$ concentration. More $\mathrm{CH}_{4}$ oxidation also leads to more $\mathrm{CH}_{2} \mathrm{O}$ production and in turn more $\mathrm{CO}$ production $\left(P_{\mathrm{CO}}\right)$, accounting for a significant fraction of the increase in this term.

\subsubsection{Impact of changing $\mathrm{NO}_{x}$ emission on $F_{\text {radicals, }}$ $F_{\mathrm{RO}_{2}}$ and $I$}

The fraction of radicals produced from bond oxidation ( $\left.F_{\text {radicals }}\right)$ and the fraction of those radicals which are $\mathrm{RO}_{2}$ $\left(F_{\mathrm{RO}_{2}}\right)$ show a slight positive increase with $\mathrm{NO}_{x}$ emission, accounting for 9 and $6 \%$ of the change in $P_{\mathrm{s}} \mathrm{O}_{3}$ respectively. This reflects changes in the partitioning of the fate of the oxidisable bonds and is largely due to the changes in $\mathrm{OH}$. As $\mathrm{OH}$ increases with $\mathrm{NO}_{x}$ emission, the rate of chemical oxidation of bonds increases at the expense of other losses, in particular deposition. The inorganic $\mathrm{RO}_{2}$ source term $(I)$ also correlates with $\mathrm{NO}_{x}$ emission, as it is largely determined by the concentrations of $\mathrm{OH}$ and $\mathrm{O}_{3}$. This change accounts for $5 \%$ of the observed change in $P_{\mathrm{s}} \mathrm{O}_{3}$.

Thus, with this new diagnostic methodology, it is evident that only $40 \%$ of the model $\mathrm{O}_{3}$ production response to changing $\mathrm{NO}_{x}$ emission is due to the direct effect of increasing $\mathrm{NO}$ concentration on the rate of $\mathrm{RO}_{2}+\mathrm{NO}$ reactions. Another $40 \%$ is due to fixing the concentration of $\mathrm{CH}_{4}$ within the model, with the final $20 \%$ due to the increased $\mathrm{OH}$ concentration competing for the available oxidisable bonds and resulting in increased $\mathrm{RO}_{2}$ production.

\subsection{Changing effective $\mathrm{CH}_{4}$ emissions}

As Fig. 2 shows $\mathrm{CH}_{4}$ to be the largest single source of oxidisable bonds, this section investigates the response of the $\mathrm{O}_{3}$ production diagnostics to changing $\mathrm{CH}_{4}$ emissions. Figure $4 \mathrm{~b}$ shows the $\mathrm{O}_{3}$ production diagnostics response to varying the $\mathrm{CH}_{4}$ emission rate within the model. As the model uses prescribed $\mathrm{CH}_{4}$ concentrations, these were varied by factors of between 0.5 and 2 from the base simulation and the $\mathrm{CH}_{4}$ emission diagnosed from the loss rate of $\mathrm{CH}_{4}$ to reaction with $\mathrm{OH}$, the only $\mathrm{CH}_{4}$ loss in the model. We describe this as the effective $\mathrm{CH}_{4}$ emission.

As effective $\mathrm{CH}_{4}$ emission increases, $\mathrm{O}_{3}$ production also increases. The standard diagnostic (Fig.4bi) shows that this increase occurs through an increased rate of reaction of $\mathrm{HO}_{2}$ and $\mathrm{CH}_{3} \mathrm{O}_{2}$ with $\mathrm{NO}$, as would be expected as these are the $\mathrm{RO}_{2}$ s produced during $\mathrm{CH}_{4}$ oxidation. The rate of other 

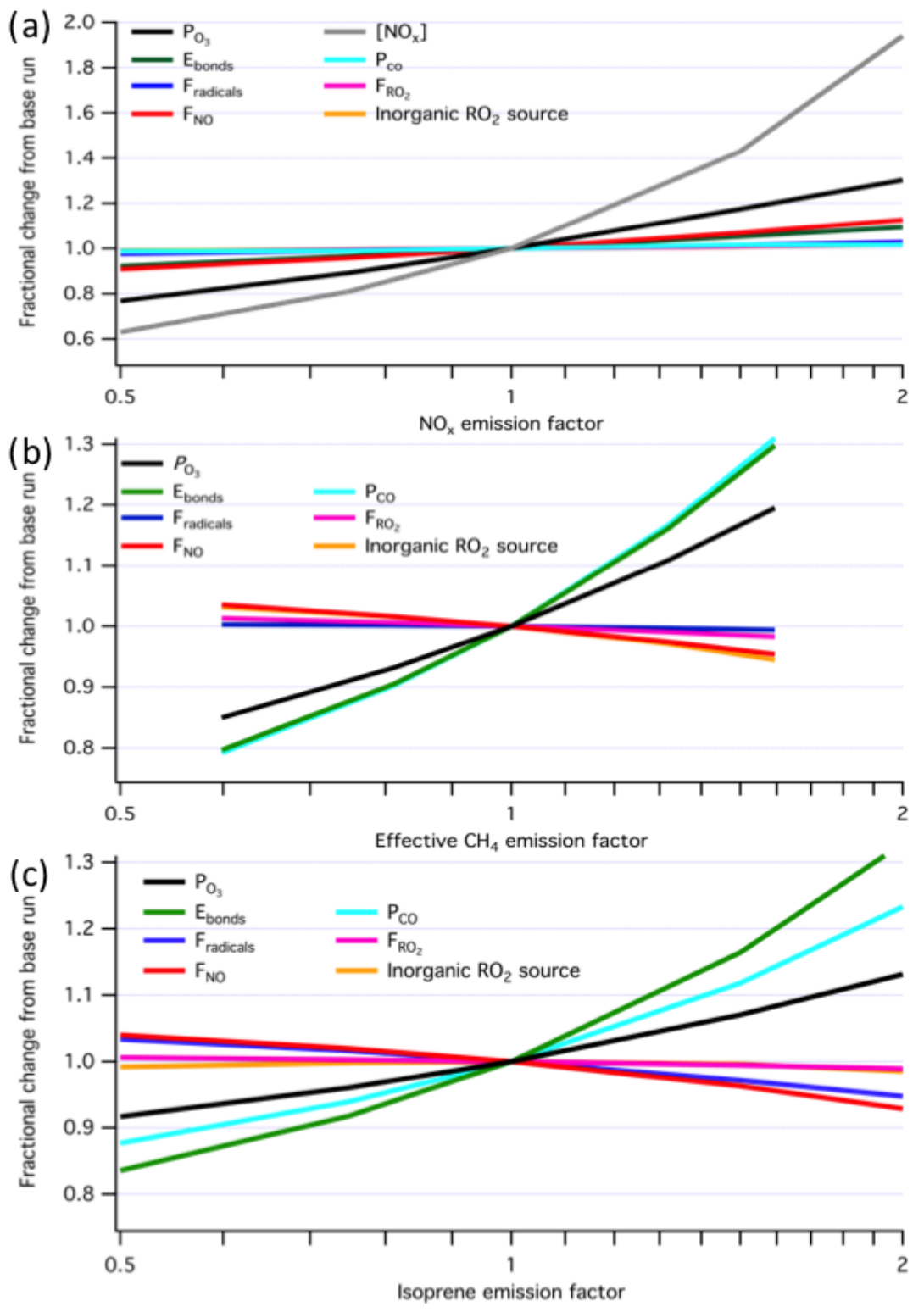

Figure 5. Fractional change in new $P_{\mathrm{S}} \mathrm{O}_{3}$ diagnostic parameters from base run against changing $\mathrm{NO}_{x}$ emission (a); effective $\mathrm{CH}_{4}$ emission (b); and isoprene emission (c).

$\mathrm{RO}_{2}+\mathrm{NO}$ reactions actually decreases slightly as $\mathrm{CH}_{4}$ emissions increase, due to lower $\mathrm{OH}$ concentrations and increased competition for $\mathrm{NO}$ from $\mathrm{HO}_{2}$ and $\mathrm{CH}_{3} \mathrm{O}_{2}$. The new diagnostic (Fig.4bii), however, shows that the increase in $\mathrm{O}_{3}$ production with increasing effective $\mathrm{CH}_{4}$ emission is not simply a result of more $\mathrm{HO}_{2}$ and $\mathrm{CH}_{3} \mathrm{O}_{2}$.

\subsubsection{Impact of changing effective $\mathrm{CH}_{4}$ emission on $F_{\text {NO }}$}

The observed change in $P_{\mathrm{S}} \mathrm{O}_{3}$ is around one-third smaller than would be expected from the increase in the oxidisable bond emission $\left(E_{\text {bonds }}\right)$ and bond production $\left(P_{\text {bonds }}\right)$ terms alone. This is due to a countering decrease in the other efficiency parameters with increasing effective $\mathrm{CH}_{4}$ emission. Figure $5 \mathrm{~b}$ shows the fractional change in all the efficiency parameters as a function of the changing effective $\mathrm{CH}_{4}$ emission. The decrease in the fraction of $\mathrm{RO}_{2}$ reacting with $\mathrm{NO}$ to produce $\mathrm{NO}_{2}\left(F_{\mathrm{NO}}\right)$ is driven by increasing $\mathrm{O}_{3}$ concentrations, which push the $\mathrm{NO} / \mathrm{NO}_{2}$ ratio towards $\mathrm{NO}_{2}$. This reduces the availability of $\mathrm{NO}$ to react with $\mathrm{RO}_{2}$, thereby reducing $\mathrm{O}_{3}$ production. This shift in the $\mathrm{NO} / \mathrm{NO}_{2}$ ratio also increases $\mathrm{NO}_{x}$ loss within the model with increasing $\mathrm{CH}_{4}$ emission, as the increased $\mathrm{CH}_{4}$ oxidation increases $\mathrm{RO}_{2}$ concentrations resulting in larger losses of $\mathrm{NO}_{2}$ via compounds 


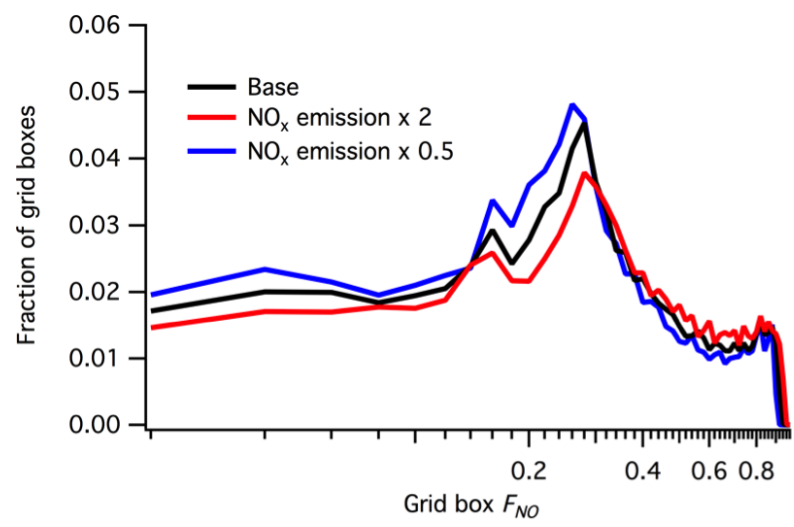

Figure 6. Effect of $\mathrm{NO}_{x}$ emission on distribution of $F_{\mathrm{NO}}$ values (log scale). $F_{\mathrm{NO}}$ values for each model grid box in the base and $\mathrm{NO}_{x}$ emission $\times 0.5$ and $\times 2$ simulations, split into $50 \times 0.02$ width bins.

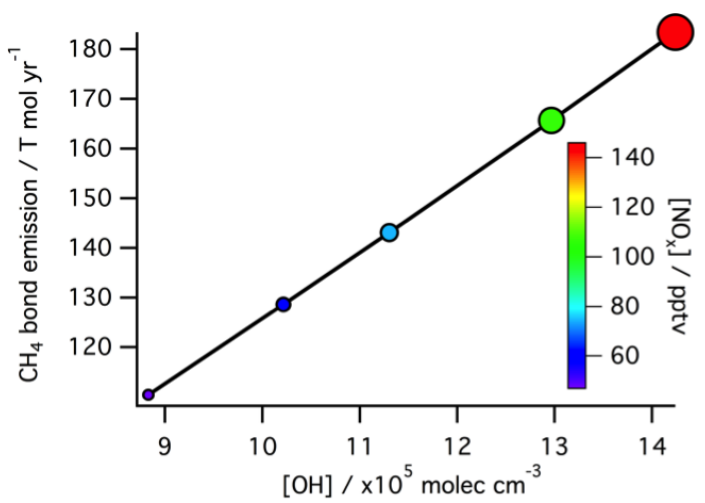

Figure 7. Effective $\mathrm{CH}_{4}$ emissions as a function of global mean $\mathrm{OH}$ concentration for simulations where $\mathrm{NO}_{x}$ emissions were changed. Marker size and colour indicate global $\mathrm{NO}_{x}$ concentration.

such as peroxyacetyl nitrate (PAN) and peroxynitric acid (PNA).

\subsubsection{Impact of changing effective $\mathrm{CH}_{4}$ emission on $\boldsymbol{E}_{\text {bonds }}$}

Increasing the effective $\mathrm{CH}_{4}$ emission results in an increase in $E_{\text {bonds. }}$. Changing the fraction of total emitted oxidisable bonds from $\mathrm{CH}_{4}$ does, however, have significant consequences for the loss mechanisms of these bonds, which influences the other efficiency parameters. Figure 8 show the split of oxidisable bond loss mechanisms in the base simulation and those with the $\mathrm{CH}_{4}$ concentration fields multiplied by 0.5 and 2 . As the effective $\mathrm{CH}_{4}$ emission increases the fraction of bonds lost via $\mathrm{OH}$ decreases, despite the actual number of oxidisable bonds lost to $\mathrm{OH}$ increasing. A larger fraction of bonds are therefore lost via the other mechanisms shown in Fig. 8 rather than reaction with $\mathrm{OH}$. As $\mathrm{CH}_{4}$ removal occurs predominantly in the free troposphere, increasing the effective $\mathrm{CH}_{4}$ emission also results in a reduction

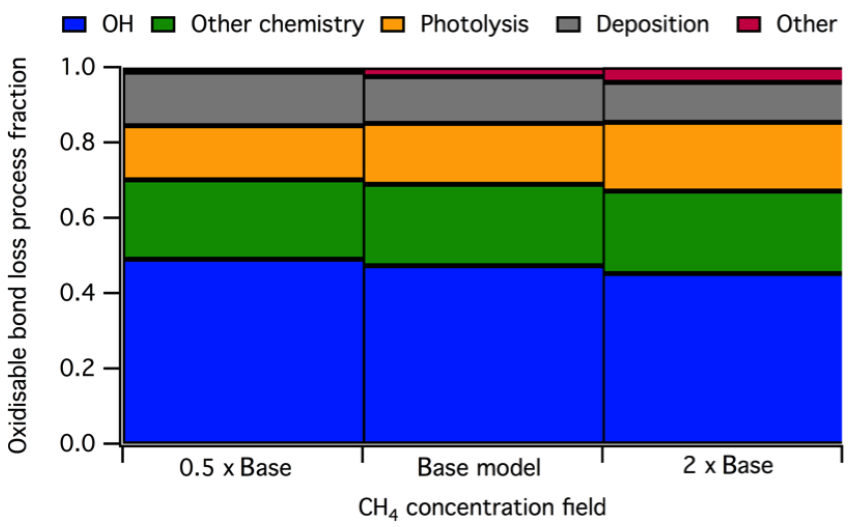

Figure 8. Oxidisable bond loss mechanism fractions under changing effective $\mathrm{CH}_{4}$ emissions $\left(0.5 \times \mathrm{CH}_{4}\right.$ concentration field, base simulation and $2 \times \mathrm{CH}_{4}$ concentration field).

in the fraction of oxidisable bonds lost via deposition. The largest fractional increase in bond loss mechanism with increasing effective $\mathrm{CH}_{4}$ emission is for photolysis, with the increase in the "other" fraction due to the increased loss of bonds to the stratosphere with increasing $\mathrm{CH}_{4}$.

\subsubsection{Impact of changing effective $\mathrm{CH}_{4}$ emission on $F_{\text {radicals }}, F_{\mathrm{RO}_{2}}$ and $I$}

The fraction of oxidisable bonds that goes on to produce radicals $\left(F_{\text {radicals }}\right)$ and the fraction of these that are $\mathrm{RO}_{2}\left(F_{\mathrm{RO}_{2}}\right)$ also decrease with increasing effective $\mathrm{CH}_{4}$ emissions. This is due to decreasing global $\mathrm{OH}$ concentration resulting from increased loss by reaction with $\mathrm{CH}_{4}$ and a decreasing $\mathrm{NO}$ concentration. This favours bond loss via pathways that produce less $\mathrm{RO}_{2}$ (e.g. $\mathrm{CH}_{2} \mathrm{O}$ photolysis). The long lifetime of $\mathrm{CH}_{4}$ compared with the majority of other sources of oxidisable bonds also results in a decrease in the fraction of bonds lost to deposition as total bond oxidation increases fractionally in the free troposphere where deposition is a less significant loss mechanism than in the boundary layer.

\subsection{Changing isoprene emission}

The species through which the oxidisable bonds are emitted has a significant impact on $\mathrm{O}_{3}$ production, due to their subsequent removal mechanisms. For example, in a simulation where the only emission of oxidisable bonds is $\mathrm{CO}, F_{\text {radicals }}$ is 0.5 and $F_{\mathrm{RO}_{2}}$ is 1 as the only $\mathrm{CO}$ sink is reaction with $\mathrm{OH}$ to produce one $\mathrm{HO}_{2}\left(\mathrm{OH}+\mathrm{CO} \rightarrow \mathrm{HO}_{2}+\mathrm{CO}_{2}\right)$. The $\mathrm{CO}$ coordinate bond, which in theory has the potential to produce two radicals, only produces one radical, which is an $\mathrm{RO}_{2}$.

Isoprene has the most complex chemistry in the model and is the second-largest source of bonds for the atmosphere after $\mathrm{CH}_{4}$ (Fig. 3). Figure 4c shows the response of the two $\mathrm{O}_{3}$ production diagnostics to varying the isoprene emission within the model. The standard diagnostic (Fig. 4ci) shows 


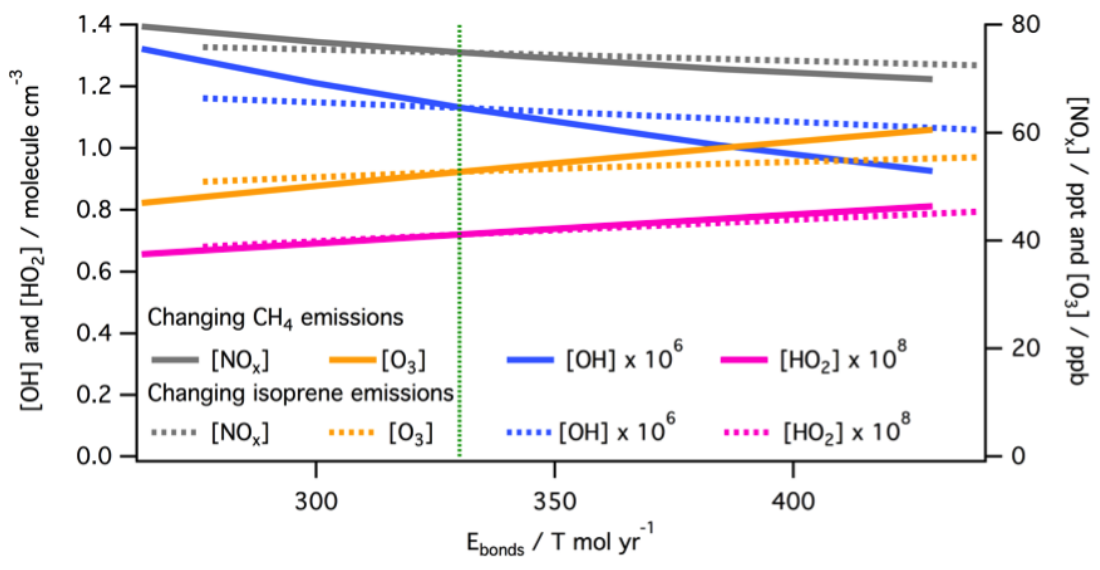

Figure 9. The effect of oxidisable bond parent species on $\mathrm{OH}, \mathrm{HO}_{2}, \mathrm{O}_{3}$ and $\mathrm{NO}_{x}$ concentrations. Global mean $[\mathrm{OH}],[\mathrm{HO} 2],\left[\mathrm{O}_{3}\right]$ and $[\mathrm{NO} x]$ for simulations where the effective $\mathrm{CH}_{4}$ emission (solid lines) and isoprene emission (dashed lines) were changed, against model $E_{\mathrm{bonds}}$. The dashed vertical green line indicates $E_{\text {bonds }}$ in the base simulation $\left(330 \mathrm{~T} \mathrm{~mol} \mathrm{yr}^{-1}\right)$.

that the most significant increase in $\mathrm{PO}_{3}$ from increasing isoprene emissions is from $\mathrm{NO}+\mathrm{HO}_{2}$ and non- $\mathrm{CH}_{3} \mathrm{O}_{2}$ peroxy radicals, with a smaller increase from $\mathrm{CH}_{3} \mathrm{O}_{2}$. The new $P_{\mathrm{s}} \mathrm{O}_{3}$ diagnostic (Fig. 4cii) again provides more insight, showing significant offsetting of around 0.5 between the terms.

\subsubsection{Impact of changing isoprene emission on $F_{\mathrm{NO}}$}

The increased isoprene emission leads to a similar change in the magnitude of the total number of oxidisable bonds emitted $\left(E_{\text {bonds }}\right)$ as the simulations in which effective $\mathrm{CH}_{4}$ emission were varied. However, the countering decrease in all of the efficiency parameters is much larger for isoprene than for $\mathrm{CH}_{4}$. Figure $5 \mathrm{c}$ shows the fractional change in the new $P_{\mathrm{S}} \mathrm{O}_{3}$ ozone production diagnostic parameters as a function of isoprene emissions compared to the base simulation. The change in $F_{\mathrm{NO}}$ is due to both a decrease in global mean $\mathrm{NO}_{x}$ concentrations with increasing isoprene and the spatial distribution of isoprene emissions. The majority of global isoprene emissions are in regions with low $\mathrm{NO}_{x}$ emissions and thus low values of $F_{\mathrm{NO}}$. Figure 9 shows a decrease in global mean $\mathrm{NO}_{x}$ and global mean $\mathrm{OH}$ concentrations with increasing isoprene emissions; however, the effect is less than that seen when $\mathrm{CH}_{4}$ is responsible for the same increase in oxidisable bond emission. This is due in a large part to the spatial scales on which the two compounds impact.

\subsubsection{Impact of changing isoprene emission on $E_{\text {bonds }}$}

As isoprene is the second-largest source of oxidisable bonds (Fig. 3), increasing the isoprene emission results in a significant increase in $E_{\text {bonds. }}$. Differences in both the spatial distribution of emissions and the oxidation chemistry of isoprene and $\mathrm{CH}_{4}$, however, means that the impact of the increases in $E_{\text {bonds }}$ on $\mathrm{O}_{3}$ production are significantly different for the two compounds. This is predominantly because the fraction of oxidisable bonds that are physically deposited for isoprene

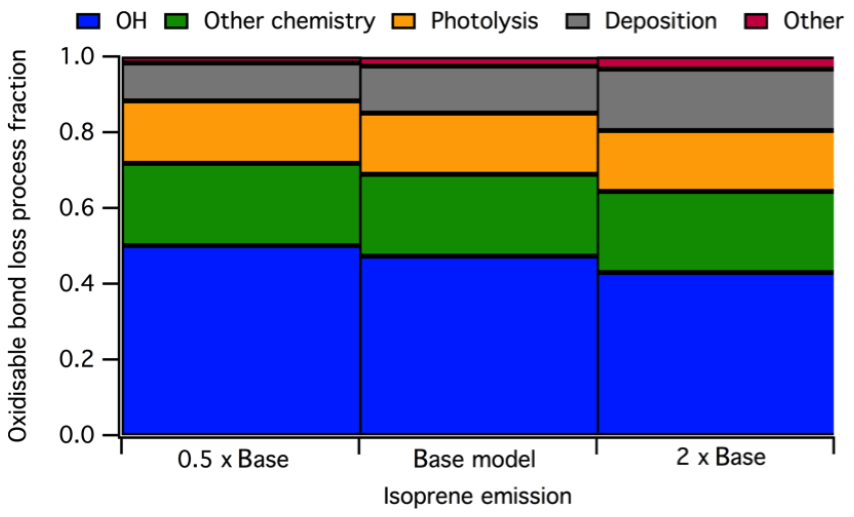

Figure 10. Oxidisable bond loss mechanism fractions under changing isoprene emissions.

is high compared to those emitted as $\mathrm{CH}_{4}$. This increase is (i) due to the higher solubility of isoprene oxidation products compared to those of $\mathrm{CH}_{4}$ and (ii) because the higher reactivity of isoprene means its oxidation occurs in the boundary layer where both dry and wet deposition are most effective.

Figure 10 shows the fate of oxidisable bonds in the base simulation and those with the isoprene emissions multiplied by 0.5 and 2 . The complex myriad of products formed during the isoprene oxidation mechanism also results in the production of many highly oxygenated multifunctional compounds with high Henry's law solubility constants, meaning they are more readily lost to deposition.

Increasing the isoprene emission also has a slight offsetting impact on the effective $\mathrm{CH}_{4}$ emission, as increased isoprene concentrations decrease $\mathrm{OH}$ concentrations and thus decrease the effective $\mathrm{CH}_{4}$ emission. A doubling in isoprene emission causes a $6 \%$ reduction in the effective emission of $\mathrm{CH}_{4}$. 


\subsubsection{Impact of changing isoprene emission on $F_{\text {radicals, }}$, $F_{\mathrm{RO}_{2}}$ and $I$}

As shown in Fig. 3cii, increasing the isoprene emission results in a reduction in all $P_{\mathrm{s}} \mathrm{O}_{3}$ efficiency parameters. The reductions in $F_{\text {radicals }}$ is due to the higher fraction of oxidisable bonds that are lost via non-radical forming pathways (e.g. deposition) for isoprene relative to the other main oxidisable bond emission sources $\mathrm{CH}_{4}$ and $\mathrm{CO}$. The slight decreases in $F_{\mathrm{RO}_{2}}$ and $I$ with increasing isoprene emission are predominantly due to changes in $\mathrm{OH}$ and $\mathrm{NO}_{x}$ (Fig. 9).

The complex chemistry of isoprene oxidation combined with the spatial distribution of isoprene emissions means that the increase in $\mathrm{O}_{3}$ production due to increases in isoprene emissions is roughly half what might be expected from the increase in oxidisable bond emission alone (i.e. if the increase was via $\mathrm{CO}$ instead of isoprene).

\section{Conclusions}

We have shown that this bond-focussed approach to $\mathrm{O}_{3}$ production provides a significantly more detailed understanding of the processes involved. The role of modelled VOC emissions and $\mathrm{O}_{3}$ burden has been reported previously (Wild, 2007; Young et al., 2013). However, previous efforts extending this to a general process-led approach have not been successful. This new approach provides a tool with which the processes controlling $\mathrm{O}_{3}$ production can be investigated and a metric by which different emissions can be compared. For example, the differing chemistry of isoprene and $\mathrm{CH}_{4}$ shows that even though their emissions of carbon mass are comparable, the atmosphere responds in different ways, with the isoprene bonds being less effective in producing $\mathrm{O}_{3}$ than $\mathrm{CH}_{4}$ bonds. By quantifying multiple steps in the $\mathrm{O}_{3}$ production process, competing changes in the system become apparent (as shown in Fig. 4bii and cii) and are thus testable. This enables the effect of model approximations on $\mathrm{O}_{3}$ production to be quantified (e.g. the effect of $\mathrm{NO}_{x}$ on $\mathrm{CH}_{4}$ emissions when using $\mathrm{CH}_{4}$ concentration fields).

This new diagnostic also points towards the importance of observational datasets for assessing our understanding of tropospheric chemistry. Although the budget presented in Fig. 2 provides an annually integrated global estimate, it points towards local comparisons that can be made to assess model fidelity. Comparisons, both their magnitude and their ratios, between observed and modelled bond concentration, bond emission and loss fluxes (e.g. OH reactivity, Yang et al., 2016, or depositional fluxes, Wesely and Hicks, 2000), and $\mathrm{O}_{3}$ production (Cazorla and Brune, 2010) would all provide comparisons for outputs from the $P_{\mathrm{s}} \mathrm{O}_{3}$ diagnostic and help assess model performance.

Future work is necessary to identify the usefulness of this approach on smaller spatial and temporal scales. For a regional modelling scale, the transport flux of bonds into the domain would need to be considered alongside the emissions of bonds. However, this might help to disentangle $\mathrm{O}_{3}$ production due to local VOC emissions from that due to VOC emissions outside of the domain. This bond focussed approach may also have usefulness on shorter timescales. For example, when considering vertical fluxes in and out of the boundary layer, a bond-centred approach could help. What fraction of the bonds emitted at the surface are exported to the free troposphere? If a measurement of reactivity flux could be made, this could be tested experimentally.

Another potentially important application is in modelmodel comparisons. Increases in our understanding of why different models calculate different $\mathrm{O}_{3}$ production and burdens has been slow (Stevenson et al., 2006; Wu et al., 2007; Young et al., 2013). Although a complete tagging like that described here is unlikely to occur for all of the models involved in the comparison, a small number of additional diagnostics is likely to produce a significantly better understanding of the models. Diagnosing (1) the total bond flux (direct emissions plus the flux for those species kept constant), (2) the rate of production of $\mathrm{RO}_{2}$ and (3) the rate of production of $\mathrm{O}_{3}$ could help differentiate why certain models produce more or less $\mathrm{O}_{3}$ than others. The ratios between these fluxes would help identify what aspect of the emissions of chemistry differs between the models.

Data availability. In order to enable replication of this work, the mechanism tagging data and approach are tabulated in the Supplement. Individual model outputs can be made available upon request

\section{The Supplement related to this article is available online at https://doi.org/10.5194/acp-17-13669-2017- supplement.}

Author contributions. All work presented here was conceived by PME and MJE. The implementation, model simulations and analysis were carried out by PME, and the manuscript was written by PME with substantial input from MJE.

Competing interests. The authors declare that they have no conflict of interest.

Acknowledgements. Peter M. Edwards was supported by NERC Grant NE/K004603/1. This work was also supported by the NERC funded BACCHUS project (NE/L01291X/1). GEOS-Chem (http://www.geos-chem.org) is a community effort, and we wish to thank all involved in the development of the model.

Edited by: Paul Monks

Reviewed by: two anonymous referees 


\section{References}

Atkins, P. W. and De Paula, J.: Atkins' Physical chemistry, 10th ed., Oxford University Press, Oxford, UK, 2014.

Cazorla, M. and Brune, W. H.: Measurement of Ozone Production Sensor, Atmos. Meas. Tech., 3, 545-555, https://doi.org/10.5194/amt-3-545-2010, 2010.

Crutzen, P. J.: Ozone production rates in an oxygen-hydrogennitrogen oxide atmosphere, J. Geophys. Res., 76, 7311-7327, https://doi.org/10.1029/JC076i030p07311, 1971.

Kroll, J. H., Donahue, N. M., Jimenez, J. L., Kessler, S. H., Canagaratna, M. R., Wilson, K. R., Altieri, K. E., Mazzoleni, L. R., Wozniak, A. S., Bluhm, H., Mysak, E. R., Smith, J. D., Kolb C. E., and Worsnop, D. R.: Carbon oxidation state as a metric for describing the chemistry of atmospheric organic aerosol, Nat. Chem., 3, 133-139, https://doi.org/10.1038/nchem.948, 2011.

Larson, R. A. and Marley, K. A.: Singlet oxygen in the environment, Environ. Photochem., 2, 123-136, 1999.

Levy, H.: Photochemistry of minor constituents in the troposphere, Planet. Space Sci., 21, 575-591, https://doi.org/10.1016/00320633(73)90071-8, 1973.

Mao, J., Paulot, F., Jacob, D. J., Cohen, R. C., Crounse, J. D., Wennberg, P. O., Keller, C. A., Hudman, R. C., Barkley, M. P., and Horowitz, L. W.: Ozone and organic nitrates over the eastern United States: Sensitivity to isoprene chemistry, J. Geophys. Res.-Atmos., 118, 1-13, https://doi.org/10.1002/jgrd.50817, 2013.

Nguyen, M. T., Sumathi, R., Sengupta, D., and Peeters, J.: Theoretical analysis of reactions related to the $\mathrm{HNO}_{2}$ energy surface: $\mathrm{OH}+\mathrm{NO}$ and $\mathrm{H}+\mathrm{NO}_{2}$, Chem. Phys., 230, 1-11, https://doi.org/10.1016/S0301-0104(97)00383-2, 1998.

Stevenson, D. S., Dentener, F. J., Schultz, M. G., Ellingsen, K., van Noije, T. P. C., Wild, O., Zeng, G., Amann, M., Atherton, C. S., Bell, N., Bergmann, D. J., Bey, I., Butler, T., Cofala, J., Collins, W. J., Derwent, R. G., Doherty, R. M., Drevet, J., Eskes, H. J., Fiore, A. M., Gauss, M., Hauglustaine, D. A., Horowitz, L. W., Isaksen, I. S. A., Krol, M. C., Lamarque, J.-F., Lawrence, M. G., Montanaro, V., Müller, J.-F., Pitari, G., Prather, M. J., Pyle, J. A., Rast, S., Rodriguez, J. M., Sanderson, M. G., Savage, N. H., Shindell, D. T., Strahan, S. E., Sudo, K., and Szopa, S.: Multimodel ensemble simulations of present-day and near-future tropospheric ozone, J. Geophys. Res.-Atmos., 111, D08301, https://doi.org/10.1029/2005JD006338, 2006.
Wesely, M. L. and Hicks, B. B.: A review of the current status of knowledge in dry deposition, Atmos. Environ., 34, 2261-2282, 2000.

Wild, O.: Modelling the global tropospheric ozone budget: exploring the variability in current models, Atmos. Chem. Phys., 7, 2643-2660, https://doi.org/10.5194/acp-7-2643-2007, 2007.

Wu, S., Mickley, L. J., Jacob, D. J., Logan, J. A., Yantosca, R. M., and Rind, D.: Why are there large differences between models in global budgets of tropospheric ozone?, J. Geophys. Res.-Atmos., 112, 1-18, https://doi.org/10.1029/2006JD007801, 2007.

Yang, Y., Shao, M., Wang, X., Nölscher, A. C., Kessel, S., Guenther, A., and Williams, J.: Towards a quantitative understanding of total OH reactivity: A review, Atmos. Environ., 134, 147-161, https://doi.org/10.1016/j.atmosenv.2016.03.010, 2016.

Young, P. J., Archibald, A. T., Bowman, K. W., Lamarque, J.-F., Naik, V., Stevenson, D. S., Tilmes, S., Voulgarakis, A., Wild, O., Bergmann, D., Cameron-Smith, P., Cionni, I., Collins, W. J., Dalsøren, S. B., Doherty, R. M., Eyring, V., Faluvegi, G., Horowitz, L. W., Josse, B., Lee, Y. H., MacKenzie, I. A., Nagashima, T., Plummer, D. A., Righi, M., Rumbold, S. T., Skeie, R. B., Shindell, D. T., Strode, S. A., Sudo, K., Szopa, S., and Zeng, G.: Preindustrial to end 21 st century projections of tropospheric ozone from the Atmospheric Chemistry and Climate Model Intercomparison Project (ACCMIP), Atmos. Chem. Phys., 13, 2063 2090, https://doi.org/10.5194/acp-13-2063-2013, 2013. 